\title{
PRODUKTIVITAS PRIMER DI WADUK IR.H.JUANDA KABUPATEN PURWAKARTA PROPINSI JAWA BARAT
}

\author{
[Primary Productivity In Ir.H.Juanda Waduk \\ District Purwakarta West Java Province]
}

\author{
Ade Sunaryo ${ }^{\bowtie}$ \\ Sekolah Tinggi Perikanan \\ Jurusan Penyuluhan Perikanan Jalan Cikaret No. 2 Bogor \\ Diterima : 10 Agustus 2017; Disetujui : 29 Agustus 2017
}

\begin{abstract}
ABSTRAK
Kondisi terkini produktivitas primer di perairan waduk Ir. H.Juanda Kabupaten Purwakarta menggambarkan jumlah energi cahaya yang diserap dan disimpan oleh jasad produser (fitoplankton) dalam bentuk bahan makanan (bahan organik), melalui proses fotosintesis dan kemosintesis, dalam periode waktu tertentu. Nilai produktivitas primer yang dihasilkan oleh organisme autotrof (fitoplankton) di perairan waduk ini mencapai kelimpahan dan keragaman fitoplankton. Dari hasil identifikasi dalam penelitian ini pada zona 1 dan 2, maka diperoleh data pada Zona 1 (Zona akreditasi) terdiri dari ; a) Bacillariophycea (141.352,21 ribu/liter), b) Chlorophycea (364.461 ribu/liter) c) Cyanophycea (1.1955.388/liter) d) Dinophycea (43.124,43 ribu/liter ) e) Euglenophycea (2.395,8 ribu/liter ). Zona 2 (di luar area akreditasi) kelimpahan Fitoplankton mencapai 222.810 ribu/liter. Data kelimpahan fitoplanton ini menjadi indikator produktivitas primer yang dapat dijadikan dasar untuk mengukur kemampuan daya dukung perairan (carrying capacity) terhadap kehidupan organisme konsumer dan dapat diduga pula kemampuan berfotosintesis untuk menghasilkan oksigen di siang hari. hasil pengamatan produktivitas primer paling tinggi terdapat pada stasiun 1 pada kisaran $104,16 \mathrm{mg} \mathrm{C} / \mathrm{m}^{3} / \mathrm{jam}$ dan $208,33 \mathrm{mg} \mathrm{C} / \mathrm{m}^{3} / \mathrm{jam}$. Pada stasiun 2 pada kisaran $-15,625 \mathrm{mg} \mathrm{C} / \mathrm{m}^{3} / \mathrm{jam}$ s.d. $72,916 \mathrm{mg}$ $\mathrm{C} / \mathrm{m}^{3} / \mathrm{jam}$. Pada stasiun $3-10,416 \mathrm{mg} \mathrm{C} / \mathrm{m}^{3} / \mathrm{jam}$ s.d. $10,416 \mathrm{mg} \mathrm{C} / \mathrm{m}^{3} / \mathrm{jam}$, dan pada stasiun 4 pada kisaran $-10,416 \mathrm{mg} \mathrm{C} / \mathrm{m}^{3} / \mathrm{jam}$ s.d. $20,833 \mathrm{mg} \mathrm{C} / \mathrm{m}^{3} / \mathrm{jam}$. Kelimpahan fitoplankton tersebut dapat berpengaruh terhadap oksigen (Disolved oxygen) yang mencapai kisaran 1,87 - 8,46 ppm, $\mathrm{pH}$ pada kisaran $6,87-7,29$, nitrat $0,390-0,815 \mathrm{ppm}$ dan suhu rata-rata pada kisaran stabil 28,3 - $30,6^{\circ} \mathrm{C}$. Sedangkan nitrit rata-rata kecil dan pada ambang batas yang aman pada kisaran $<0,001-0,013$ ppm karena aktifitas oksidasi tinggi oleh oxygen.
\end{abstract}

Kata Kunci : Waduk, diversitas fitoplankton, produktivitas primer, carrying capacity

\begin{abstract}
Current conditions of primary productivity in the waters of a reservoir of IR. H. Juanda Purwakarta Regency describes the amount of energy of the sun light that is absorbed and stored by the remains of the producers (phytoplankton) in the form of food ingredients (organic matter), through the process of photosynthesis and Chemosynthesis, within a certain time period. The primary productivity of the value generated by the organism autotroph (phytoplankton) in the waters of the reservoir reached the abundance and diversity of phytoplankton. Identification of the results in this study on zone 1 and 2, then the retrieved data in the zone 1st (zone of accreditation) consists of; a) Bacillariophycea (141,352.21 000/litre), b) Chlorophycea (364,461 000/litre) c) Cyanophycea (1.1955.388/liter) d) Dinophycea (43,124.43 000/litre) e) Euglenophycea $(2,395.8$ 000/litre). Zone 2nd (outside area of accreditation) phytoplankton abundance reached 222,810 000/litre. The abundance of data phytoplankton this be the primary productivity indicators that can be relied upon to measure the ability of power support's waters (carrying capacity) against the life of consumer organisms and photosynthetic ability also may be suspected for produce oxygen during the day. The highest primary productivity observation

$\triangle$ Penulis Korespondensi

Alamat Surel : adesunaryo2015@gmail.com
\end{abstract}


results were found at station 1 in the range of $104.16 \mathrm{mg} \mathrm{C} / \mathrm{m} 3 / \mathrm{hrs}$ and $208.33 \mathrm{mg} \mathrm{C} / \mathrm{m} 3 / \mathrm{hrs}$. At station 2 in the range of $-15,625 \mathrm{mg} \mathrm{C} / \mathrm{m} 3 / \mathrm{hr}$ s.d. $72.916 \mathrm{mg} \mathrm{C} / \mathrm{m} 3 / \mathrm{hr}$. At station 3 $10.416 \mathrm{mg} \mathrm{C} / \mathrm{m} 3 / \mathrm{hr}$ s.d. $10,416 \mathrm{mg} \mathrm{C} / \mathrm{m} 3 / \mathrm{hrs}$, and at station 4 in the range of $-10.416 \mathrm{mg} \mathrm{C} /$ $\mathrm{m} 3$ / hr s.d. $20.833 \mathrm{mg} \mathrm{C} / \mathrm{m} 3 / \mathrm{hrs}$. The abundance of phytoplankton can influence on oxygen (Disolved Oxygen) which climbed $1.87-8.46 \mathrm{ppm}$, pH range of $6.87-7.29$, nitrate $0.390-0$, $815 \mathrm{ppm}$ and average temperatures in the range of stable $28.3-30.6^{\circ} \mathrm{C}$. While nitrite average small and on a safe threshold in the range $0.001-0<013 \mathrm{ppm}$, due to the high oxidation activity by oxygen.

Keywords : reservoirs, primary productivity, phytoplankton diversity, carying capacity.

\section{PENDAHULUAN}

\section{Latar Belakang}

Perkembangan data dan informasi tentang kondisi zonasi Waduk Ir. H. Djuanda, telah dikenal masyarakat sejak dibangun dengan sebutan Waduk Jatiluhur. Zonasi waduk terletak di Kabupaten Purwakarta, Provinsi Jawa Barat. Luas Waduk Ir. H. Djuanda adalah 8.300 ha dan berada pada ketinggian110 m dpl. Sejak tahun 1967 waduk tersebut mulai digenangi air hingga saat dilakukan penelitian pada kondisi opersional perairan yang stabil, jika dihitung usia waduk telah mencapai usia 50 tahun. Dilihat dari fungsinya serta peruntukannya bahwa waduk ini adalah untuk, pengendali banjir pembangkit tenaga listrik dan pengairan.Untuk mendukung kehidupan biota air, khususnya ikan; tidak ada prioritas terutama budidaya yang terstruktur. Produktivitas primer menjadi sesuatu yang harus dipertanyakan dari aktifitas perairan waduk yang meningkat seiring dengan berkembangnya populasi jumlah species dari waktu ke waktu secara dinamis yang terutama atau khususnya berlaku pada perairan waduk Ir. H. Djuanda. Kondisi hidrologi waduk Ir. H. Djuanda ini sangat dipengaruhi oleh sumber air yang memasuki dan menggenaginya. Sumber air utama yang masuk ke waduk Ir. H. Djuanda ini, selain berasal dari Sungai Citarum, juga berasal dari Sungai Cilalawi serta limpasan/run off air tanah dan juga air hujan yang sering kali mengubah badan air terutama pada saat perubahan iklim pancaroba yang tidak terkendali adakalanya menimbulkan upwelling yang dapat juga besar pengaruhnya terhadap dinamika hidrologi perairan waduk.

Produktivitas primer menggambarkan jumlah pembentukan bahan organik baru per satuan waktu. Senyawa organik yang baru akan terbentuk melalui proses fotosintesis. Kegiatan fotosintesis di perairan waduk dilakukan oleh fitoplankton dan tanaman air (Boyd 1979). Produktivitas primer ini sering dinyatakan dalam $\mathrm{mg} \mathrm{C} / \mathrm{m} 3 / \mathrm{jam}$ atau $\mathrm{mg}$ $\mathrm{C} / \mathrm{m} 3 /$ hari untuk satuan volume air dan 
$\mathrm{mg} \mathrm{C} / \mathrm{m} 2 /$ jam atau $\mathrm{mg} \mathrm{C} / \mathrm{m} 2 /$ hari satuan luas kolom air. Menurut Suwigyo (1983) produktivitas primer dapat dipakai untuk menentukan keseburan suatu perairan. Klasifikasi tingkat kesuburan tersebut adalah: 0-200 mg C/m3/hari termasuk oligotrofik, $200-750 \mathrm{mg} \mathrm{C} / \mathrm{m} 3 / \mathrm{hari}$ termasuk mesotrofik dan lebih dari 750 mg $\mathrm{C} / \mathrm{m} 3 /$ hari termasuk eutrofik (Triyatmo dkk 1997).

Produktivitas primer dapat diartikan sebagai kandungan bahan-bahan organik yang dihasilkan dari proses fotosintesis oleh organisme berklorofil dan mampu mendukung aktivitas biologi di perairan tersebut. Produktivitas primer dapat diketahui nilainya dengan cara mengukur perubahan kandungan DO yang dihasilkan dari proses fotosintesis. Produksi oksigen dapat menjadi dasar pengukuran adanya kesetaraan yang kuat antara $\mathrm{O} 2$ dan pangan yang dihasilkan (Odum 1970).

Produktivitas primer dalam bentuk plankton dianggap salah satu unsur yang penting pada salah satu mata rantai perairan. Plankton-plankton yang ada dalam perairan akan sangat berguna dalam menunjang sumberdaya ikan, terutama dari golongan konsumen primer. Densitas dan diversitas fitoplankton dalam perairan sangat dipengaruhi oleh kondisi lingkungan tersebut. Densitas fitoplankton akan tinggi apabila perairan yang didiami subur (Boyd 1982).

Ada beberapa faktor yang mempengaruhi tinggi rendahnya produktivitas primer perairan. Faktorfaktor tersebut bisa dibagi menjadi 3 yaitu faktor kimia, fisika, dan biologi. Faktor kimia seperti kandungan fosfat dan nitrat adalah merupakan hara yang pentong untuk pertumbuhan dan reproduksi phytoplankton. Bila dikaitkan dengan faktor fisika dan level air maka pada level air yang rendah dengan tersedianya sinar matahari menghasilkan produktivitas primer yang tinggi. Disamping faktor kimia dan fisika, faktor biologi seperti perbandingan komposisi biomassa phytoplankton dan zooplankton, memperlihatkan bahwa jumlah individu dalam populasi phytoplankton jauh lebih besar dibandingkan dengan jumlah individu dalam populasi zooplankton, dan karena yang melakukan fotosintesa didalam ekosistem perairan adalah phytoplankton, ini berakibat langsung terhadap tingginya produktivitas primer (Kaswadji 1976).

Kesuburan atau produktivitas primer pada waduk meliputi plankton, DO, $\mathrm{CO} 2$, dan lain-lain. Produktivitas primer merupakan energi utama yang mendasari struktur tropik ekosistem perairan dan merupakan tanggapan 
terhadap kondisi fisik-kimia yang ada. Perubahan masukan unsur hara ke dalam perairan akan berpengaruh terhadap produktivitas primer.

\section{TUJUAN PENELITIAN}

1. Mengetahui tingkat produktivitas primer pada zona genangan waduk dan kandungan bahan-bahan organik yang dihasilkan waduk.

2. Mengetahui faktor apa saja yang dapat mempengaruhi tingkat produktivitas primer
3. Mengetahui produktivitas primer waduk pada zona stasiun genangan air waduk yang berbeda.

\section{BAHAN DAN METODE}

Penelitian produktivitas primer di waduk Ir. H.Juanda telah dilaksanakan pada bulan Agustus 2017. Stasiun penelitian dibagi menjadi 2 (dua) Zona yaitu Zona I disebut Zona akreditasi, dan Zona II dengan sebutan Zona non-akreditasi. Pengambilan sampel pada Zona I dilakukan pada 4 (empat) stasiun yang mewakili perairan Waduk Ir. H. Juanda, Jawa Barat (Gambar 1).

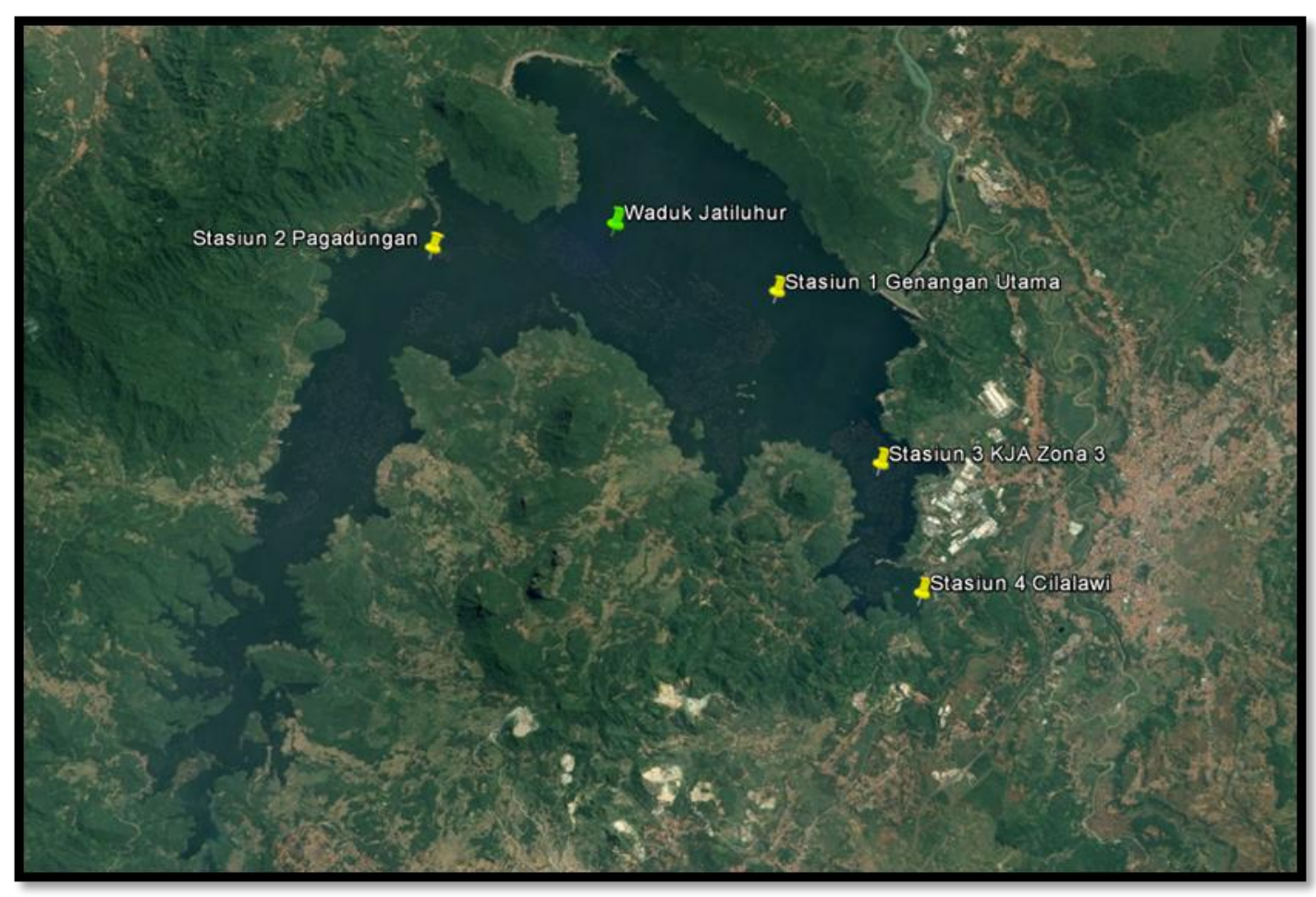

Gambar 1. Zona I Tempat Pengambilan Sampel Penelitian

Stasiun1: daerah Genangan utama

Stasiun 2: daerah dekat dengan inlet utama dari Waduk Ir. H. Juanda

Stasiun 3: daerah budidaya ikan keramba jaring apung (KJA)

Stasiun 4: daerah dekat dengan pemukiman 
Sampel air diambil dengan menggunakan kemmerer water sampler secara vertikal pada kedalaman perairan (40 cm, dan 80 meter).

Pengukuran dilakukan dengan mengukur laju oksigen yang terlarut dalam perairan waduk dan mengukur faktor abiotik. Nilai produktivitas primer bersih pada setiap zonasi kedalaman di tiap titik dapat diketahui dengan dilakukan penghitungan produksi oksigen sebagai berikut:

1. Produktivitas primer bersih = produktivitas primer kotor respirasi.

2. Produktivitas primer kotor $=$ kadar oksigen terlarut dalam botol terang pada akhir pengukuran - kadar dari nilai oksigen $\mathrm{mg} / \mathrm{L}$ dikalikan dengan faktor 375,36 (Michael, 1994).

\section{Alat dan Bahan}

1. Alat

a.Secchidisc

b.Termometer

c.pHmeter

d. botol oksigen,gelas ukur, mikroskop, embern, pipet tetes, pipet ukur, elenmeyer, planktonet, Sedwich Raffer, botol film, plastik hitam dan putih, karet, tali rapia.

2. Bahan

Reagen O2, larutan $\mathrm{H} 2 \mathrm{SO} 4$ pekat, larutan $\quad \mathrm{Na} 2 \mathrm{~S} 2 \mathrm{O} 31 / 80 \mathrm{~N}, \quad$ larutan MnSO4, indikator amilum, larutan formalin $4 \%$

Prosedur Penelitian dan Cara Kerja

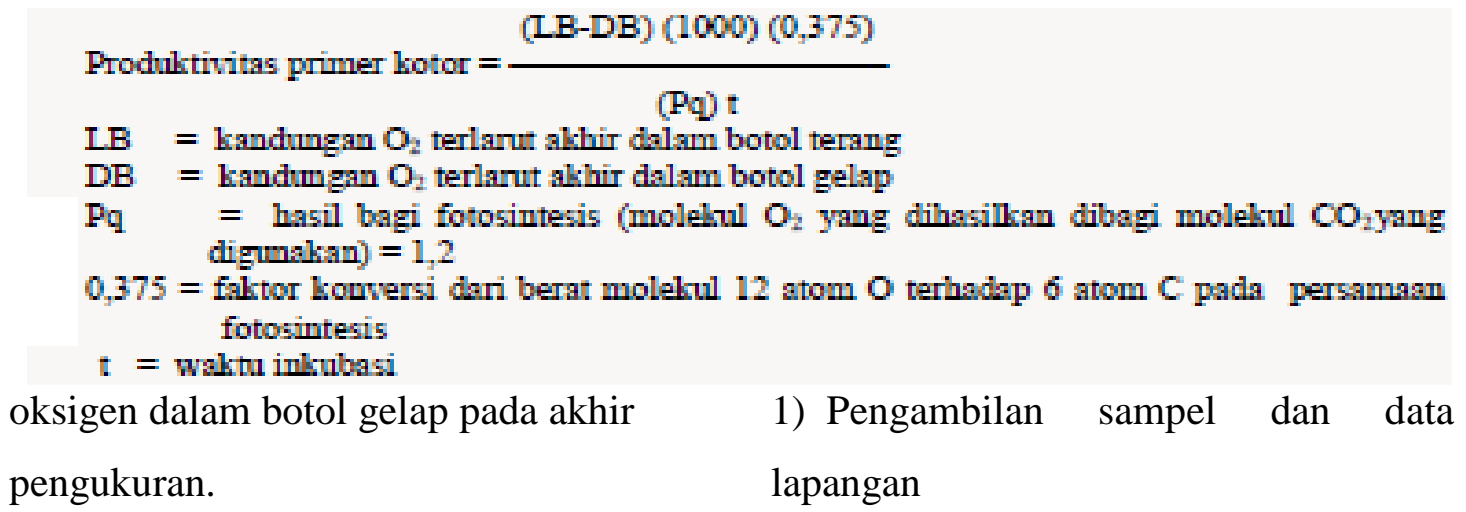

oksigen dalam botol gelap pada akhir

1) Pengambilan sampel dan data lapangan pengukuran.

3. Respirasi $=$ kadar oksigen di awal pengukuran - kadar oksigen dalam botol gelap pada akhir pengukuran.

Nilai produktivitas primer dinyatakan sebagai $\mathrm{mg} / \mathrm{C} / \mathrm{m}^{3}$ didapatkan a. Menyiapkan semua alat dan bahan dengan sebaik-baiknya sebelum pelaksanaan

b. Mencuci botol gelap-terang sampai bersih dengan air bersih bebas organisme 
c. Mengisi botol terang I dengan air permukaan dan mengukur kandungan $\mathrm{O} 2$ terlarutnya

d. Mengisi botol gelap-terang II, III dan IV dengan air permukaan dan menginkubasi pada kedalaman yang diinginkan pada waktu matahari belum cukup intensif bersinar (sekitar pukul 06.00 WIB)

e. Mengambil botol gelap-terang II pada jam 10.00 WIB dan mengukur kandungan $\mathrm{O} 2$ terlarutnya. Mengukur kandungan $\mathrm{O} 2$ terlarut pada saat itu sebagai kontrol kualitas air

f. Mengambil botol gelap-terang II pada jam 14.00 WIB dan mengukur kandungan $\mathrm{O} 2$ terlarutnya. Mengukur kandungan $\mathrm{O} 2$ terlarut pada saat itu sebagai kontrol kualitas air

g. Mengambil botol gelap-terang II pada jam 18.00 WIB dan mengukur kandungan $\mathrm{O} 2$ terlarutnya. Mengukur kandungan $\mathrm{O} 2$ terlarut pada saat itu sebagai kontrol kualitas air

2) Pengambilan sampel dan pengamatan plankton

a. Mengambil sampel air sebanyak 2050 liter (a) dan memampatkan ke dalam botol yang sudah diketahui volumenya (b) dengan menggunakan jaring plankton/planktonet untuk mengetahui kepadatan plankton

b. Memfiksasi dengan menggunakan larutan formalin $4 \%$ c. Memasukkan sampel plankton ke dalam sedgwick Rafter hingga penuh dengan menggunakan pipet tetes dan menutup dengan gelas penutup. Memastikan volume sedgwick Rafter yang digunakan (c)

d. Mengamati di bawah mikroskop dan menghitung semua plankton yang terdapat dalam sedgwick Rafter (d)

Kepadatan Plankton $=\frac{d x b / c}{a}$ individu/Liter

\section{HASIL DAN PEMBAHASAN}

\section{HASIL}

Penelitian terhadap produktivitas primer waduk Ir. H. Juanda bertujuan untuk mengetahui produktivitas suatu perairan serta mengetahui faktor-faktor yang diduga mempengaruhi pada produktivitas primer suatu perairan waduk. Parameter fisik yang digunakan adalah suhu air dan udara serta kecerahan, parameter kimia yang digunakan adalah kandungan DO (botol gelap dan terang) dan parameter biologi adalah densitas dan diversitas plankton. Penelitian kali ini mengambil tempat di Zona I (zona akreditasi).

a. Stasiun 1

Pengukuran produktivitas primer dilakukan pada pukul 12.00 WIB. Pada kedalaman $\quad 40 \quad \mathrm{~cm}$ produktivitas primernya adalah 208,33 mg C/m3/jam 
dan pada kedalaman $80 \mathrm{~cm}$ adalah 104,16 mg C/m3/jam. Nilai Produktivitas primer pada kedalaman 40 $\mathrm{cm}$ menjadi tinggi karena pada kedalaman tersebut kecerahannya lebih tinggi daripada pada kedalaman $80 \mathrm{~cm}$ sehingga fitoplankton banyak di daerah tersebut dan disebabkan oleh suhu air dan udara yang rendah serta kecerahan yang tinggi. Tingginya densitas plankton juga merupakan faktor yang berpengaruh dan kebanyakan didominasi fitoplankton yang menghasilkan oksigen dari fotosintesis. Hal ini membuat kadar DO kontrol pada saat pengukuran menjadi tinggi. Pada kedalaman $80 \mathrm{~cm}$, nilai produktivitas primernya rendah karena kecerahan yang rendah dan disebabkan oleh bertumpuknya sampah sehingga air menjadi kotor dan naik suhunya. Keadaan ini diperparah dengan kurangnya kandungan unsur hara dalam perairan yang membuat plankton tidak mendapat cukup nutrisi untuk beraktivitas. Pengukuran produktivitas primer dilakukan pada pukul 18.00 WIB pada kedalaman $40 \mathrm{~cm}$ adalah 218,75 $\mathrm{mg} \mathrm{C} / \mathrm{m} 3 /$ jam. Nilai tersebut lebih tinggi dibandingkan dengan kedalaman $80 \mathrm{~cm}$ adalah 88,541 mg C/m3/jam karena pada jam 18.00 WIB matahari sudah mulai tenggelam sehingga sinar matahari pada kedalaman $40 \mathrm{~cm}$ bisa masuk dengan baik sehingga proses fotosintesis bisa terjadi sedangkan pada kedalaman $80 \mathrm{~cm}$ sinar matahari tidak bisa masuk sehingga proses fotosintesis tidak terjadi dan disebabkan oleh bertumpuknya sampah sehingga air menjadi kotor dan naik suhunya. Keadaan ini diperparah dengan kurangnya kandungan unsur hara dalam perairan yang membuat plankton tidak mendapat cukup nutrisi untuk beraktivitas.

b. Stasiun 2

Pengukuran produktivitas primer dilakukan pada pukul 12.00 WIB, sampel diletakkan mulai pukul 06.00 WIB. Pada kedalaman $40 \mathrm{~cm}$ dan kedalaman $80 \mathrm{~cm}$ nilai produktivitas primernya sama yaitu sebesar $72,916 \mathrm{mg}$ $\mathrm{C} / \mathrm{m} 3 /$ jam. Nilai ini tinggi yang disebabkan karena suhu air dan udara yang rendah serta kecerahan yang tinggi. Tingginya densitas plankton juga merupakan faktor yang berpengaruh dan kebanyakan didominasi fitoplankton yang menghasilkan oksigen dari fotosintesis. Hal ini membuat kadar DO kontrol pada saat pengukuran menjadi tinggi. Pengukuran produktivitas primer dilakukan pada pukul 18.00 WIB pada kedalaman $40 \mathrm{~cm}$ mendapatkan nilai produktivitas primer sebesar -26,041 mg $\mathrm{C} / \mathrm{m} 3 /$ jam. Nilai produktivitas primer 
pada kedalaman $80 \mathrm{~cm}$ adalah $-15,625$ $\mathrm{mg} \mathrm{C} / \mathrm{m} 3 / \mathrm{jam}$.

\section{c. Stasiun 3}

Pada pukul 06.00 WIB hanya dilakukan pengambilan sampel untuk kemudian dilakukan pengukuran pada pukul 12.00 dan 18.00 WIB. Nilai produktivitas primer pada pukul 12.00 WIB pada kedalaman $40 \mathrm{~cm}$ sebesar 0 dan kedalaman $80 \mathrm{~cm}$ sebesar 10,416 mg $\mathrm{C} / \mathrm{m} 3 / \mathrm{jam}$. Nilai Produktivitas primer pada kedalaman $80 \mathrm{~cm}$ menjadi tinggi karena nilai kecerahan dan suhu pada kedalaman tersebut sangat cocok untuk fitoplankton melakukan fotosintesis dan zooplankton melakukan respirasi. Pada kedalaman $40 \mathrm{~cm}$ suhu permukaan sangat panas sehingga plankton kurang suka pada keadaan tersebut. Pada jam 18.00 WIB, nilai produktivitas primer kedalaman 40 sebesar $-10,416 \quad \mathrm{mg}$ $\mathrm{C} / \mathrm{m} 3 / \mathrm{jam}$. Pada kedalaman $80 \mathrm{~cm}$ nilai produktivitas primernya sebesar 10,416 mg C/m3/jam. Hal tersebut dikarenakan oleh keberadaan fitoplankton yang banyak melakukan fotosintesis dan tingginya densitas plankton juga merupakan faktor yang berpengaruh dan kebanyakan didominasi fitoplankton yang menghasilkan oksigen dari fotosintesis. Hal ini membuat kadar DO kontrol pada saat pengukuran menjadi tinggi.

\section{d. Stasiun 4}

Pada pukul 06.00 WIB hanya dilakukan pengambilan sampel untuk kemudian dilakukan pengukuran pada pukul 12.00 dan 18.00 WIB. Produktivitas primer pada pukul 12.00 WIB pada kedalaman $40 \mathrm{~cm}$ dan $80 \mathrm{~cm}$ nilainya sama yaitu sebesar 0. Hal ini disebabkan oleh keseimbangan antara produsen (plankton) dan konsumer. Biota konsumer membutuhkan plankton yang ada di bagian outlet pada genangan utama untuk menjadi makanannya sehingga menyebabkan nilai produktivitas primernya rendah. Pada jam 18.00 WIB, nilai produktivitas primer kedalaman $40 \mathrm{~cm}$ sebesar 20,833 mg C/m3/jam. Hal tersebut disebabkan oleh pada kedalaman tersebut sinar matahari masih bisa menembus daerah tersebut sehingga fitoplankton banyak yang melakukan fotosintesis dan suhu air pada kedalaman tersebut sangat di senangi oleh fitoplanton, dan bahanbahan organik terdapat banyak pada kedalaman tersebut sehingga menimbulkan daerah tersebut nilai produktivitas primernya rendah. Pada kedalaman $80 \mathrm{~cm}$ nilai produktivitas primernya sebesar $-10,416 \quad \mathrm{mg}$ $\mathrm{C} / \mathrm{m} 3 / \mathrm{jam}$.

\section{PEMBAHASAN}


Berdasarkan hasil pengamatan produktivitas primer paling tinggi terdapat pada stasiun 1 pada kisaran 104,16 mg C/m3/jam dan 208,33 mg $\mathrm{C} / \mathrm{m} 3 / \mathrm{jam}$. Pada stasiun 2 pada kisaran -15, $625 \mathrm{mg} \mathrm{C/m3/jam} \mathrm{s.d.} \mathrm{72,916} \mathrm{mg}$ C/m3/jam. Pada stasiun $3-10,416 \mathrm{mg}$ C/m3/jam s.d. 10,416 mg C/m3/jam, dan pada stasiun 4 pada kisaran -10,416 mg C/m3/jam s.d. 20,833 mg C/m3/jam .

Genangan utama waduk adalah tempat yang luasnya lebih besar stasiun 1 dan 2 sehingga plankton yang hidup di daerah tersebut lebih banyak. Hal tersebut menyebabkan banyaknya plankton. Nilai produktivitas primer yang tinggi dipengaruhi oleh faktor fisik, kimia dan biologi. Stasiun 1 dan 2 lebih baik memiliki kualitas perairan yang baik dan produktivitas primer perairan yang baik dibandingkan dengan zonasi stasiun 3 dan 4. Tinggi dan rendahnya nilai produktivitas primer perairan tersebut sangat dipengaruhi oleh aktvitas organisme perairan dalam men-suply oksigen terlarut dan penggunaan oksigen terlarut tersebut serta kondisi-kondisi lain yang juga mempengaruhi adalah suhu dan kecerahan yang mencakup tinggi rendahnya intensitas cahaya matahari yang masuk ke dalam perairan tersebut serta densitas planktonnya yang melakukan proses fotosintesis tadi.
Nilai produktivitas primer pada zonasi stasiun 3 dan 4 rendah disebabkan salah satunya oleh blooming yang berlebihan mengakibatkan bahan organik mati. Penumpukan yang berlebihan akan mengakibatkan zat amoniak meningkat pada zona 3 dan 4 sehingga akan meracuni plankton dan membuat terjadinya penurunan produktivitas primer. Blooming yang tidak terkendali menyebabkan nilai DO yang tersedia cukup berkurang dan menambah terjadinya persaingan atau kompetisi konsumsi biota dalam perairan juga mempengaruhi produktivitas primer perairan seperti pada zona stasiun 3 dan 4. Ekosistem yang terbuka merupakan tempat wisata membuat waduk ini cukup kotor. Banyaknya sampah yang dibuang ke dalam perairan membuat perairan menjadi tercemar.

Menurut Triyatmo dkk (1997) bahwa klasifikasi tingkat kesuburan tersebut adalah: 0-200 mg C/m3/hari termasuk oligotrofik, 200-750 mg C/m3/hari termasuk mesotrofik dan lebih dari 750 $\mathrm{mg} \mathrm{C} / \mathrm{m} 3 /$ hari termasuk eutrofik.

Diversitas dan kelimpahan Fitoplankton serta kualitas air yang prima sebagai indikator Caryying Capacity dapat merekomendasikan suatu konsep dasar Pengelolaan Produktivitas untuk Rekomendasi Penggunaan Waduk secara tepat. 


\section{SIMPULAN}

1. Produktivitas primer adalah nilai kesuburan pada suatu zona 1, 2, 3 dan 4 Waduk; kandungan bahan-bahan organic dan padatan plankton dari hasil identifikasi dalam penelitian ini pada zona 1 dan 2, maka diperoleh data pada Zona 1 (Zona akreditasi) terdiri dari ;

a) Bacillariophycea $\quad(141.352,21$ ribu/liter),

b) Chlorophycea (364.461 ribu/liter)

c) Cyanophycea (1.1955.388/liter)

d) Dinophycea (43.124,43 ribu/liter )

e) Euglenophycea (2.395,8 ribu/liter). Zona 2 (di luar area akreditasi) kelimpahan Fitoplankton mencapai 222.810 ribu/liter. yang dihasilkan dari proses fotosintesis oleh organisme dan yang mampu mendukung aktivitas biologi di perairan sekitar waduk Ir.H.Juanda.

2. Tingkat produktivitas primer dipengaruhi oleh faktor fisik (suhu dan kecerahan), kimia (DO, CO2, pH dan alkalinitas) dan biologi (densitas dan diversitas plankton).

Kelimpahan fitoplankton tersebut dapat berpengaruh terhadap oksigen (DO) yang mencapai kisaran 1,87 - 8,46 ppm, pH pada kisaran $6,87-7,29$, nitrat $0,390-$ $0,815 \mathrm{ppm}$ dan suhu rata-rata pada kisaran stabil $28,3-30,6^{\circ} \mathrm{C}$. Sedangkan nitrit rata-rata kecil dan pada ambang batas yang aman pada kisaran $<0,001 \quad$ 0,013ppm karena aktifitas oksidasi tinggi oleh oxygen.

3. Produktivitas primer perairan waduk pada stasiun 1 dan 2 lebih tinggi dibandingkan dengan produktivitas primer Zonasi stasiun 3 dan 4, diduga disebabkan oleh konsentrasi akumulasi sebaran bahan organik yang berbeda pada setiap stasiun.

\section{SARAN}

Saran yang dapat kami sampaikan agar penelitian dilanjutkan pada parameter kualitas air secara menyeluruh dan terprogram untuk dapat dijadikan acuan dalam pengelolaan waduk Ir, Juanda dimasa yang akan datang.

\section{PERSANTUNAN}

Ucapan terimakasih disampaikan kepada Ketua Jurusan Penyuluhan Perikanan, Sekolah Tinggi Perikanan, yang telah memfasilitasi pendanaan penelitian ini, kepada para penyuluh perikanan di lima lokasi waduk yang yang telah memfasilitasi bantuan peralatan dan data, selama penelitian.

\section{DAFTAR PUSTAKA}


Boyd, C.E. 1979. Pengelolaan Kualitas Air. Dirjen Perikanan. Jakarta

Djumara, Noorsyamsa. 2007. Modul 3 Sumber Daya Alam Lingkungan Terbarukan dan Tidak Terbarukan Diklat Teknis Pengelolaan Lingkungan Hidup di Daerah (Environmental Assesment and Management). Jakarta.

Kaswadji, R. F. 1976. Studi Pendahuluan Tentang Penyebaran dan Kemelimpahan Phytoplankton di Delta Upang, Sumatera Selatan. Karya Ilmiah Fakltas perikanan IPB Bogor. Bogor.

Mahmuddin. 2009. Produktivitas Primer Ekosistem. http://mahmuddin.Wordpres s.com/2009/09/09/produktiv itas-primer-eksosistem/ Diakses pada tanggal 15 Oktober 2017.

Mahmudi, M. 2005.Produktivitas Peraiaran. Fakultas Perikanan Universitas Brawijaya. Malang.

Nybakken, J., 1992. Biologi Laut. PT. Gramedia Pustaka Raya. Jakarta.

Nybakken, J. W. 1992. Biologi Laut Suatu Pendekatan Ekologi. Cetakan ke-2. PT. Gramedia Pustaka Utama. Jakarta

Odum, E.D. 1970. Fundamentaly of Ecology 3th ed. W.B Sounders Company. Philadelphia.

Sinurat, Gokman. 2009. Skripsi: Studi Tentang Nilai Produktivitas Primer Di Pangururan Perairan Danau Toba. Departemen Biologi. Fakultas Matematika Dan Ilmu Pengetahuan Alam. Universitas Sumatera Utara. Medan.
Sudaryanti. 2004. Produktivitas Perairan (Sekunder). Fakultas Perikanan dan Ilmu Kelautan. Universitas Brawijaya. Malang.

Triyatmo, B., Rustadi, Djumanto, S.B., Priyono, Krismono, N Sehenda, dan Kartamihardja, E.S., 1997. Studi Perikanan Di Waduk Sermo: Studi Biolimnologi. Lembaga Penelitian UGM Bekerjasama Dengan Agricultural Research Management Project. BPPP. 65 hal

Vryzas. 2008. Sejarah dan Ruang Lingkup Ekologi dan Ekosistem. www. google.com. Diakses tanggal 15 Oktober 2017.

Wiadnyana, Ngurah Nyoman. 2003. Peranan Plankton Di Dalam Ekosistem Perairan Indonesia, Lautan Red Tide. Pusat Penelitian Oseanografi (POG) Lembaga Ilmu Pengetahuan Indonesia (LIPI). Jakarta.

Wiryanto, A P. 2001. Produktifitas Primer Perairan Waduk Cengklik Boyolali. www. google.com. Diakses tanggal 15 Oktober 2017. 